$R M x A C, \mathbf{5 3}, 151-154(2021)$

(c) 2021: Instituto de Astronomía, Universidad Nacional Autónoma de México

https://doi.org/10.22201/ia.14052059p.2021.53.30

\title{
THE USE OF ROBOTIC TELESCOPES IN THE SCIENCE-IES PROJECT IN SPAIN
}

\author{
A. J. Castro-Tirado ${ }^{1,2}$, F. J. P. Cáceres ${ }^{3,4}$, A. Castellón ${ }^{5}$, C. J. Pérez del Pulgar ${ }^{2}$, A. Cordón ${ }^{6}$, J. Márquez ${ }^{7}$, \\ M. L. Mayordomo ${ }^{8}$, Á. Iturbe ${ }^{9,10}$, and J. M. Leyva Fernández ${ }^{11}$
}

\section{RESUMEN}

ScienceIES es una forma distintiva de enseñar Astronomía y otras disciplinas científicas, centrándose en estudiantes de secundaria (de 15 a 17 años). ScienceIES es el nombre del proyecto iniciado en 2010 a nivel regional en Andalucía (sur de España) que une los sistemas educativos y científicos para involucrar a los estudiantes de último curso de Secundaria y primero de Bachillerato. Algunos de los proyectos de Astronomía se basan en el uso de telescopios robóticos, como los de la red mundial BOOTES. Presentamos algunos de estos proyectos.

\section{ABSTRACT}

ScienceIES is a distinctive way to teach Astronomy and other scientific disciplines, focusing in high-school students (age 15-17). ScienceIES is the name of the project started in 2010 at regional level in Andalucía (south Spain) pulling together the educational and scientific systems with students in the target. Some of the Astronomy projects are based on the use of robotic telescopes, such as the ones of the BOOTES worldwide network. Some of the projects are presented here.

Key Words: education — telescopes

\section{INTRODUCTION}

Since the 1980's, much technical progress has been made in robotic telescope provision to end users via a variety of different approaches and the power of robotic telescopes to transform science education has been voiced since then by multiple sources (Gomez and Fitzgerald 2017).

The Bradford robotic telescope paved the way to teach Astronomy in schools in the late 1990's and

\footnotetext{
${ }^{1}$ Instituto de Astrofísica de Andalucía (IAA-CSIC), Granada, Spain.

${ }^{2}$ Unidad Asociada Departamento de Ingeniería de Sistemas y Automática, Escuela Superior de Ingeniería Industrial, Universidad de Málaga, Spain.

${ }^{3}$ Science Department, I.E.S. Pablo de Sanz, Marbella (Málaga), Spain.

${ }^{4}$ Departamento de Enseñanza de las Ciencias Experimentales. Universidad de Granada, Spain.

${ }^{5}$ Departamento de Álgebra, Geometría y Topología, Facultad de Ciencias, Universidad de Málaga, Spain.

${ }^{6}$ Instituto de Hortofruticultura Subtropical y Mediterránea "La Mayora" (UMA-CSIC), Algarrobo Costa (Málaga), Spain.

${ }^{7}$ Colegio Los Olivos, Puerto de la Torre, Málaga, Spain.

${ }^{8}$ Colegio Padre Jacobo, Fundación Victoria, Málaga, Spain.

${ }^{9}$ Studentship, I.E.S. Pablo de Sanz, Marbella (Málaga), Spain.

${ }^{10}$ Studentship, Facultad de Ciencias, Universidad, Granada, Spain.

${ }^{11}$ Studentship, Facultad de Ciencias, Universidad del Pais Vasco, Bilbao, Spain.
}

early 2000's, starting in the UK (Camacho et al. 2009; Baruch 2015).

Motivated by the decreasing number of students at Spanish Universities choosing Science, Technology, Engineering and Mathematics (STEM) in the early 2000's, at Andalusian level a group of teachers led by F. J. Cáceres contacted with scientists in order to work together to bring motivation and interest to high-school students at several locations in Andalusia, starting in Granada downtown in 2010 (Lupión and Cáceres 2017). This was the start of the PIIISA Project (Program for Initiation into Research and Innovation in High Schools in Spain, PIIISA, from its Spanish acronym), later dubbed ScienceIES.

The educational background for this program was the societal need for more scientifically literate and motivated students. At the same time, it was often felt that the current educational system is not linked closely enough to the world of science. Consequently, an innovative program was developed which joined together high school students, their teachers and scientists for practical problem solving, working together in schools and laboratories, as well as across schools (see Alché et al. (2015) for instance). In order to assess the effects of the program, students were requested to write evaluations, to participate in interviews, and to complete surveys. Data analysis was guided by various educational theories on learning, didactics, experience, etc., selected on the basis 

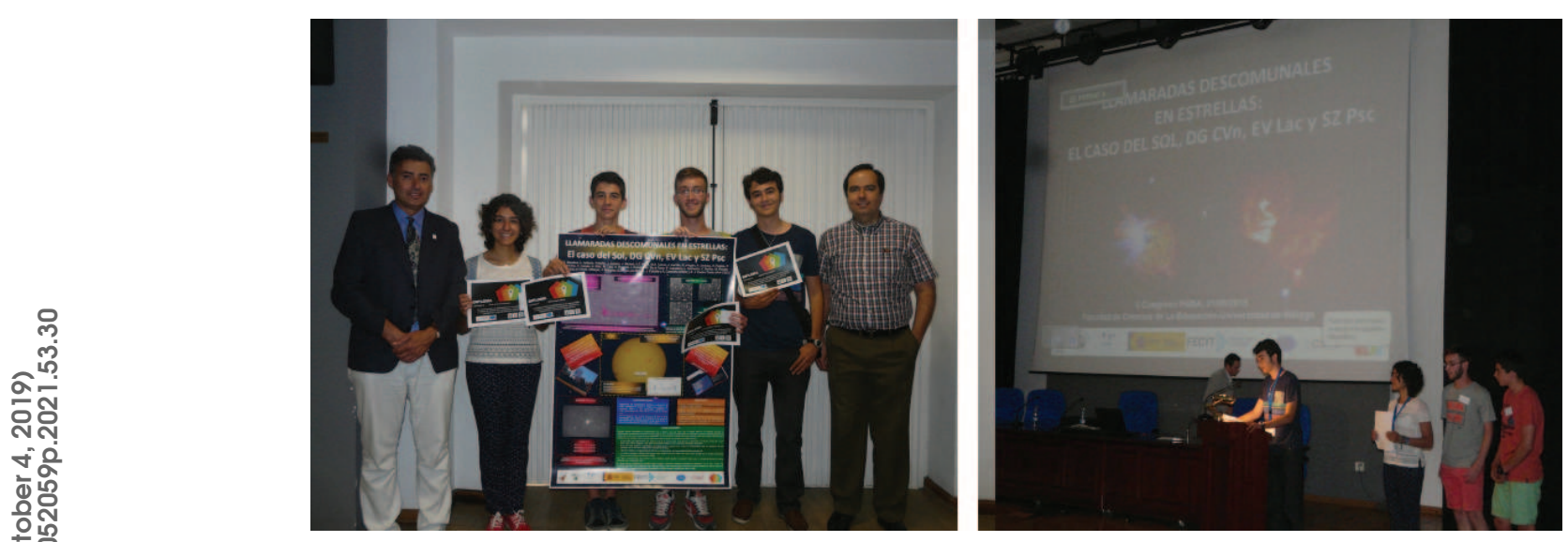

Fig. 1. The one-day Andalusian ScienceIES Conference in 2015 where all students gathered. Left: The poster depicting the research work on extreme active stars carried out by 22 high-school students from Colegio Los Olivos (with four representing them) together with the scientist (A. J. Castro-Tirado) and the teacher (J. Márquez). Right: an excerpt of their oral presentation They extensively sheduled observations at the BOOTES-2 telescope for their research project.
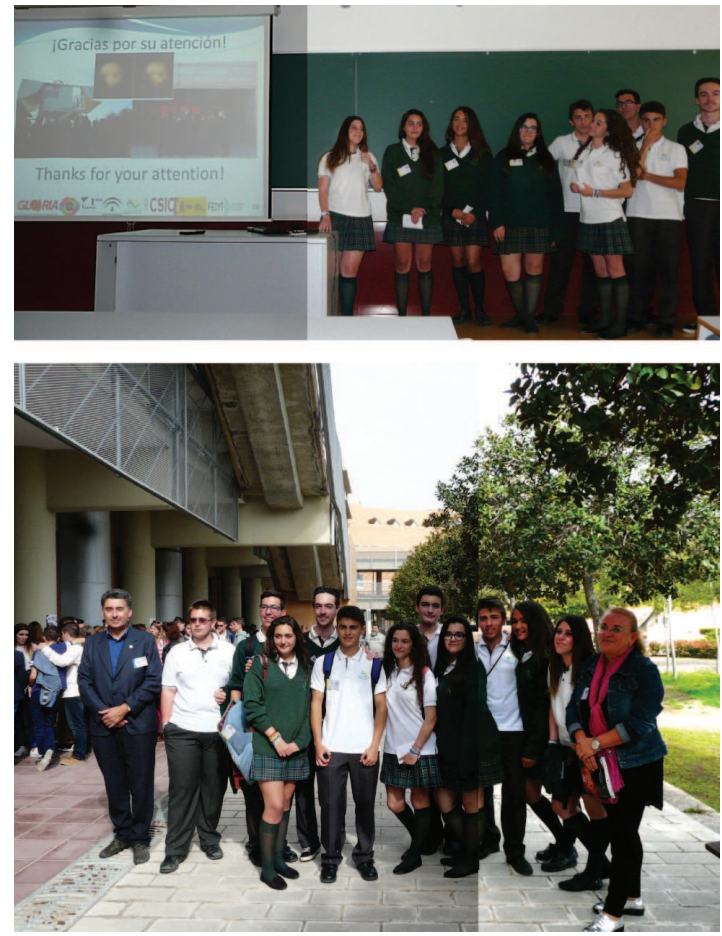

Fig. 2. The 2016 ScienceIES Conference. Top: The talk on the research work based on the BOOTES-3 observations prior to the New Horizons Pluto flyby, given by 12 high-school students from Padre Jacobo school. Bottom: The students together with the scientist (A. J. CastroTirado) and the teacher (M. L. Mayordomo).

of preliminary analyses. The findings showed that students generally developed functionality, sensitivity and social competences.

Following the deployment of the BOOTES Global Network of telescopes in Spain in 1998
(Castro-Tirado et al. 1999), spreading worldwide (Castro-Tirado et al. 2012), and the time allocation of some of the BOOTES telescopes observing time for the GLORIA EU/FP7 Project (Castro-Tirado et al. 2014), the use of these robotic instruments for citizen science in general (and teaching at both primary and secondary school level) was seriously considered. With the extension of the PIIISA (Science IES) Project to other Andalusian provinces, such as Málaga in 2013, A. J. Castro-Tirado, BOOTES Principal Investigator (PI) and GLORIA co-PI, proposed to include astronomical research projects in PIIISA (ScienceIES) making use of robotic telescopes so the students could gather their own data as part of the proposed scientific problem they had to solve.

\section{METHODOLOGY}

ScienceIES is intended for teenagers who could handle a computer and were interested in a wide range of scientific disciplines running from all scientific branches to other disciplines such as psicology, paleography, etc. One of the most demanded always scientific projects has been Astronomy.

For this purpose, and considering many teenagers living in heavily populated towns and having never seen the starry night, it was important to show them what is happening in the sky with our Solar System, the nearby stars, the Milky Way and the rest of the galaxies.

In ScienceIES we wanted to provide the support and answers that they rarely received in primary school complementing what they are being taught in secondary school. Furthermore, we wanted them to get acquainted with the scientific method, and involve them in real research projects carried out 

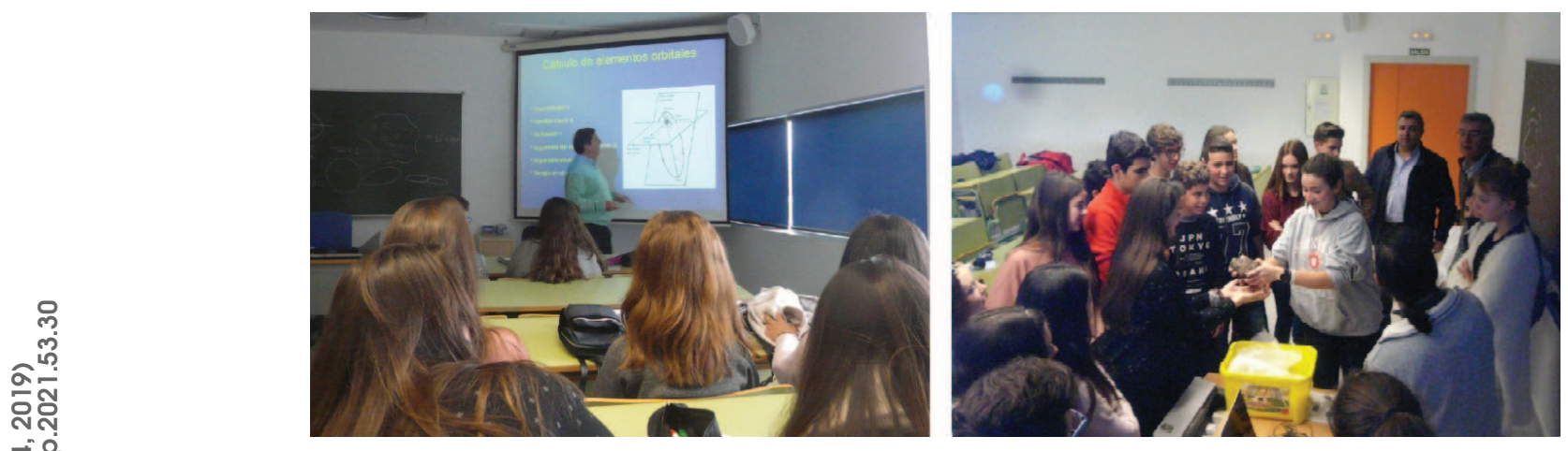

Fig. 3. Left: The research work on meteors storms (2017) was introduced by a lecture given by A. Castellón on the orbits of parent systems at the UMA Faculty of Sciences. Right: A complementary lecture was given on fireball and meteorites in which some samples were shown (and even touched!) by the enthusiastic students (females most of them). This was given at the UMA Faculty of Engineering. Some of these students have already started in 2020 the first year undergraduate course, three years after they participated in the ScienceIES project.

together with real researchers at Spanish Universities and Goverment Research State Agencies (such as CSIC, INTA, etc.).

During 3 days (usually in mid Dec, late Jan and early Mar) students abandon their high-schools and attend the ScienceIES introductory lectures (Dec), visit the university laboratories or research centres (such as the BOOTES-2 astronomical station) (Jan) and carry out the experiments or conduct the remote astronomical observations (Feb), presenting the preliminary results to the high-school teacher and scientists who (both of them) are supervising their joint research between the students and the scientist.

Finally, at regional level, a one-day conference is hold in Spring (usually early May) in one of the Andalusian provinces main towns, where all research works are displayed (posters) whereas a selected one (per province) is presented as an oral talk (i.e. eight oral talks are given) following the opening conference normally given by a world class Spanish scientist.

\section{RESULTS}

Since 2013, a handful of astronomical projects making use of robotic telescopes (particularly the ones from the BOOTES Network) have been accomplished and with results being presented at the corresponding 1-day conference hold in Spring every year.

The projects carried out so far using robotic telescopes are the following ones:

- Observing the Sun in real time and calculating the Wolf number (with GLORIA) (2013-14).

- Giant stellar flares. The case of DG CVn, EV LAC and SZ Psc (2014-15).

- Pluto before and after the visit of the New Horizons probe flyby (2015-16).

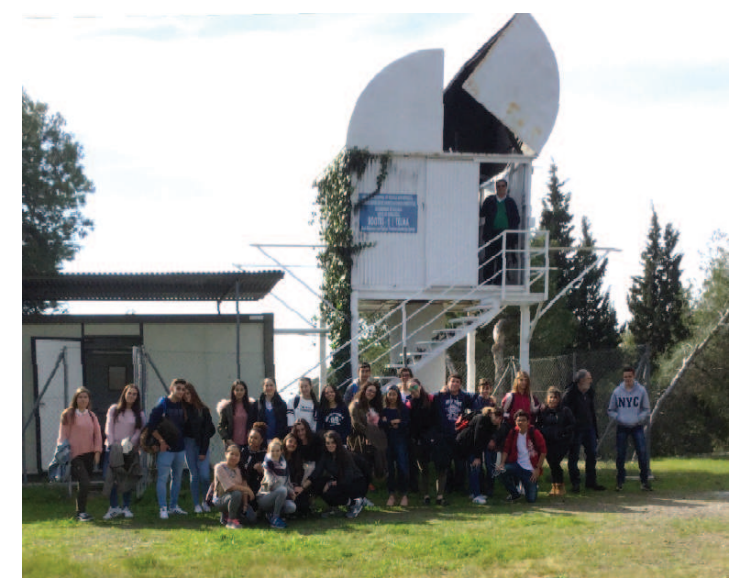

Fig. 4. The visit to the BOOTES-2 astronomical station in Algarrobo-Costa of high-schools students in Málaga participating in ScienceIES in 2017.

- Meteors Storms: their origin and their composition (2016-17).

- The Local Group of galaxies (2017-18).

- The structure of the Universe and Astrobiology (2018-19).

- X-ray binaries (2019-20).

\section{CONCLUSION}

ScienceIES is a distinctive way to teach Astronomy and other scientific disciplines, focusing in highschool students (age 15-17). ScienceIES is the name of the project started in 2010 at regional level in Andalucía (south Spain) pulling together the educational and scientific systems with students in the target. Since 2013, some of the ScienceIES Astronomy 

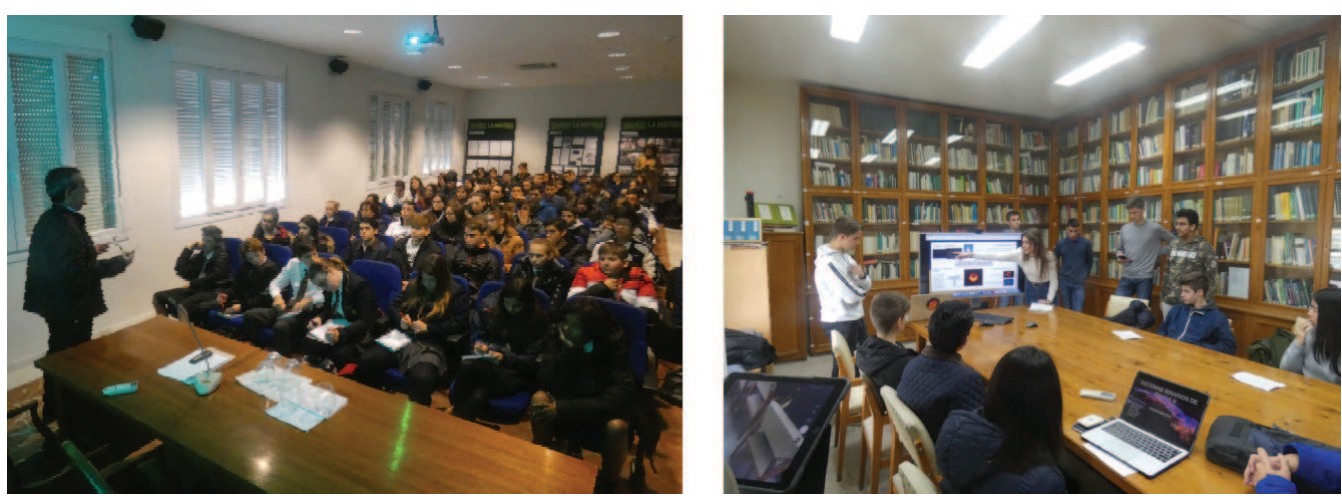

Fig. 5. Left: The introductory talk about the IHSM "La Mayora" given by A. Cordón in 2020. Right: The students at the IHSM library presenting their research work focused on X-ray binaries (black holes and neutron stars).

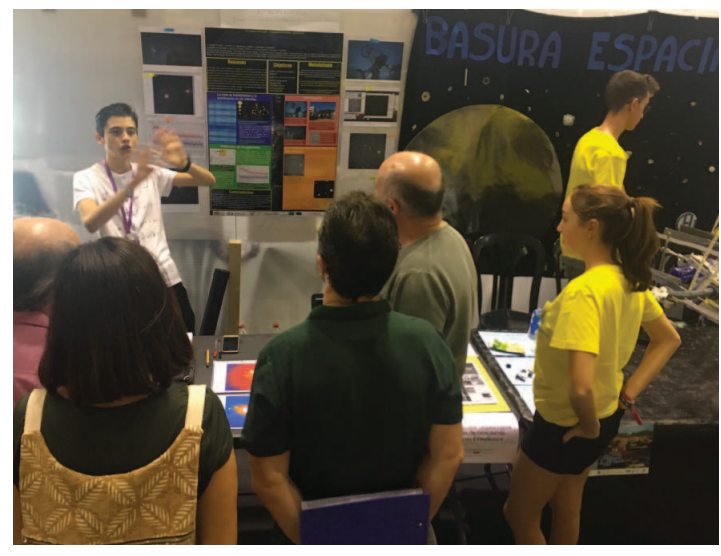

Fig. 6. A. Iturbe, one of the high-schools students using the BOOTES-2 robotic telescope, explaining to a wider audience during the related conference "Science in Action" hold in Alicante (Spain) in 2019 the results he and other students achieved during the ScienceIES work months earlier. Their research project was related to the structure of the Universe and Astrobiology.

projects are based on the use of robotic telescopes, such as the ones of the BOOTES worldwide network.

After all these years, we can claim the interest in STEM studies in Andalusia has greatly increased and the ScienceIES Project has been most essential in this regard. For additional information see https://piiisaandalucia.blogspot.com/ and http://www.journalscienceies.blogspot.com.
Acknowledgements: We acknowledge support from the BOOTES team members and particularly E. Fernández García. We also thanks F. J. Gálvez and F. Espartero for their assistance in 2017. This work has been partially supported by the Spaanish Science Ministry "Centro de Excelencia Severo Ochoa" Program under grant SEV-2017-0709.

\section{REFERENCES}

Alché, J. D., Espinosa, M., Martínez-Abarca, F., \& Palma, J. M. 2015, High School Students for Agricultural Science Research, Ed. Estación Experimental del Zaidín, Granada

Baruch, J. 2015, A\&G, 56, 2.18

Camacho, A., Holt, R., Marley, S. \& Roberts, S. 2009, School Science Review, 90, 73

Castro-Tirado, A. J., Soldán, J., Bernas, M. et al. 1999, A\&AS, 138, 583

Castro-Tirado, A. J., Jelínek, M., Gorosabel, J. et al. 2012, ASInC, 7, 313

Castro-Tirado, A. J., Sánchez-Moreno, F. M., Pérez del Pulgar, C. J. et al. 2014, RMxAC, 45, 104

Gomez, E. L. and Fitzgerald, M. T. 2017, AstRv, 13, 26

Lupión, T. \& Cáceres, F.J.P. 2017, Apostando por las vocaciones científicas desde la Educación Secundaria. Oportunidades mediante investigaciones con el programa Science-IES (PIIISA), UMA Editorial, Málaga 